\title{
OBJETIVOS DE DESARROLLO DEL MILENIO. ¿HACIA UNA POLÍTICA DE ESTADO MUNDIAL?*
}

\author{
Eduardo MARTín FRACALOSSI**
}

\begin{abstract}
SUMARIO: I. Conferencias previas. II. Conferencias posteriores. III. En territorio argentino. IV. Desatino. V. Política de Estado mundial. VI. Conclusión.
\end{abstract}

Perpetuando el interesante interrogante de Matías E. Ilivitzky “¿Es posible la realización de los objetivos del milenio?", tomo como punto de partida sus argumentaciones y parafraseando a Tomas Kuhn, la ciencia se caracteriza porque cada intérprete agrega sus postulados, cambiando los paradigmas, haciendo alterar teorías produciendo una Revolución científica, siendo esta la base de todo crecimiento y superación cultural.

Por todo ello, es que me atrevo a incorporar mi punto de vista para ser analizado y criticado por quien lo examine, y de este modo alterar postulados para producir una Revolución científica.

Reflexiono que los Objetivos de Desarrollo del Milenio (ODM), van siendo una política de Estado mundial. Con ello me refiero a que luego de la Declaración del Milenio en septiembre de 2000, a ningún Estado se le ocurrió restar valor jurídico y político a esta gran iniciativa de la Organización de las Naciones Unidas (ONU). Todas las políticas de Estado se caracterizan por permanecer incólumes entre diferentes administraciones y son decididas con visión de futuro, a ello me refiero a 20,30 o más años.

Si bien la Declaración del Milenio estableció una pauta para el cumplimiento de los ODM en un plazo de 15 años, ninguna administración resolvería volver las cosas al estado anterior luego de 2015, personalmente creo que vendrán nuevos ODM o el refuerzo de ellos para lograr el fin de las ONU: la paz y la seguridad internacional.

* Artículo recibido el 13 de junio de 2008 y aceptado para su publicación el 4 de agosto de 2008.

** El autor es director para el NEA de la Asociación para las Naciones Unidas de la República Argentina. 
En un mundo en el que se habla que las civilizaciones chocarán por las fallas culturales que separan a estas, porque estas diferencias no son sólo reales sino básicas, porque el mundo interactúa cada vez más por el proceso de modernización económica y cambio social que está separando a las naciones de sus identidades, por el crecimiento de la conciencia de civilización por el efecto del doble papel de occidente, junto a que las diferencias culturales son menos mudables, y los regionalismos económicos dependen de convergencias culturales, creo que los ODM vienen a superar esta crisis y a identificarnos como ciudadanos del mundo.

Sabemos quiénes somos sólo cuando sabemos quiénes no somos y con frecuencia sólo cuando sabemos contra quién estamos.

De las tres tradiciones analíticas sobre las relaciones internacionales la que mayor se ajusta al estudio de los ODM es el liberalismo por el problema central que aborda, que es el conflicto y la cooperación. Porque mientras los realistas se concentran en la guerra y la paz, y los marxistas en la dominación y subordinación, los liberales adoptan una visión más amplia, los conflictos económicos, ideológicos, culturales, sociales, religiosos y étnicos tanto como militares y es aquí donde se abordan los ODM por la amplitud de las temáticas que buscan satisfacer.

Las organizaciones internacionales y no gubernamentales, los Estados, partidos políticos, grupos de interés, medios y los individuos son los actores para esta visión. Nosotros como asociación civil somos un actor de las relaciones internacionales según esta mirada, permitiéndonos negociar en la política, en compromisos nacionales en busca de intereses públicos, porque nuestra visión y fines son ellos, colaborar para con los principios y valores de ONU.

\section{CONFERENCIAS PREVIAS}

Los ODM sintetizan los puntos de trabajos elaborados en la Conferencia Mundial de Educación para Todos, la Cumbre Mundial por la Infancia, la Conferencia de la ONU sobre Medio Ambiente y Desarrollo, la Conferencia Internacional de Nutrición, la Conferencia Mundial sobre Derechos Humanos, la Conferencia Internacional sobre Población y Desarrollo, la Cumbre Mundial para el Desarrollo Social, la IV Conferencia Mundial sobre la Mujer, la Conferencia de la ONU sobre Asentamientos Humanos y la Cumbre Mundial de la Alimentación. 


\section{CONFERENCIAS POSTERIORES}

Luego de la Declaración del Milenio han sucedido dos conferencias que siguen lo iniciado en la Cumbre del Milenio: la Conferencia Internacional sobre la Financiación para el Desarrollo de Monterrey (México), celebrada en 2002, que fue un gran paso adelante en los esfuerzos por alcanzar los ODM. En esta conferencia se insistió en la necesidad de frenar la tendencia decreciente de la asistencia oficial para el desarrollo y se asumió el compromiso de reducir la carga de la deuda, sobre todo la correspondiente a los países menos adelantados. Y la Cumbre Mundial de Johannesburgo, donde se planteó que la sostenibilidad ambiental de ninguna manera puede considerarse un lujo que puede posponerse. En ella se reafirmó el principio 7 relativo a "las responsabilidades comunes pero diferenciadas", consagrado en la Declaración de Río emanada de la Conferencia de las Naciones Unidas sobre el Medio Ambiente y el Desarro1lo, celebrada en 1992. Conforme a este principio, se reconoce explícitamente la deuda ambiental que los países desarrollados han adquirido con el resto de la comunidad internacional, como consecuencia de las externalidades y los efectos acumulados derivados de su trayectoria de industrialización, y se plantea el fundamento político para que los países industrializados asuman mayores compromisos en el cumplimiento de las metas ambientales acordadas en el ámbito multilateral.

\section{EN TERRITORIO ARGENTINO}

Ubicándonos en la esfera nacional, en la provincia de Corrientes se promovió un hecho que cambió quizás lo hasta aquí acaecido, pues introdujo una novedad en materia de derecho público, provincial y municipal y me atrevo a decir en materia de derecho internacional, por lo menos hasta lo conocido por mi, incorporándose en materia constitucional provincial elementos del derecho internacional publico.

El año pasado (2007) se reformó la Constitución Provincial Correntina y se añadieron los ODM en las disposiciones transitorias, cláusula primera, en la cual se tranza en un Pacto Correntino para el Crecimiento Económico y el Desarrollo Social las Bases para la formulación de políticas de Estado siendo 
la formulación institucional de las coincidencias alcanzadas para la elaboración de políticas de estado, con el propósito de sostenerlas en el tiempo como denominador común para obtener el crecimiento económico, erradicar la pobreza y lograr la inclusión social, en consonancia con los objetivos de desarrollo del milenio, establecidos por la Organización de las Naciones Unidas y adaptados a la realidad provincial.

Lo anterior es lo que reza la nueva Carta Constitucional Provincial Correntina.

\section{DESATINO}

Los 8 objetivos, las 18 metas y los 48 indicadores mensurables tristemente en territorio nacional, luego de la deshonra y descrédito del Instituto Nacional de Estadísticas y Censos, son la antesala de un brecha de tiempo sin datos fidedignos para corroborar el avance de los ODM a nivel nacional y como consecuencia no poder aportar al sistema de la ONU datos ecuánimes para la elaboración de los informes regionales y mundiales del secretario general y de los organismos técnicos especializados de las Naciones Unidas.

\section{POLÍTICA DE ESTADO MUNDIAL}

Como lo planteaba al comienzo, según los datos que se manejan y los 39 millones de personas que participaron de la Campaña Levántate contra la Pobreza el año pasado (2007) en el marco de la Campaña del Milenio por los ODM, estamos viendo como nace, se difunde y apoya una política de Estado mundial. Por primera vez en la historia todos los ciudadanos del mundo confluyen en ideales comunes y los sostienen.

Si bien la ONU es una organización internacional y no supra estatal, cada día cobran mayor relevancia sus decisiones, y son los parámetros para decidir en las políticas nacionales, provinciales y municipales. De allí que hablo de un concierto de ideales de los ciudadanos del mundo.

Los ODM han dejado de ser sólo palabras de la Declaración del milenio, las universidades, las escuelas, la sociedad civil y el Estado han hecho suyos estos objetivos y los han tomado como propios. Es así que quienes conformamos la Comisión para la Región NEA, hicimos el lanzamiento de la comisión en una Conferencia sobre los ODM. 
En tal oportunidad disertaron representantes de cada uno de los poderes del Estado provincial y el coordinador de los ODM de Presidencia de la nación, quienes en una académica y crítica exposición brindaron datos e información de lo que han cumplido y lo que falta por hacer para con los ODM.

Como principal desatención se deliberó en la falta de comunicación y trabajo en conjunto de los poderes del Estado y estos con la sociedad civil. Se destacó el rol del Poder Judicial para reducir la discriminación contra la mujer y del Poder Ejecutivo respecto a la pobreza. Se llamó a la reflexión a los legisladores para la legislación y control respecto del desarrollo sustentable y procurar que las provincias sean fieles a los ODM y coordinen sus políticas con la nación para que los esfuerzos y las buenas ideas no se diluyan.

\section{CONCLUSIÓN}

Los ODM, aunque no existieran en sí mismo, trascienden a la humanidad toda, y el cumplimiento de ellos se podría exigir de igual modo, por que en ellos está resumida la esencia humana.

Los ODM resumen décadas de conferencias y encuentros mundiales y los indicadores mensurables en plazo y calidad de gestión nos brindan el avance de ellos a nivel mundial, regional y estadual. Por ello, como se expresó el señor secretario general en el Informe 2007, “debemos disponer de información fiable y puntual para formular políticas y estrategias necesarias para garantizar el progreso, controlar el desarrollo y hacer factibles los ODM".

¿Estamos bien encaminados para que en 2015 se pueda decir que no hemos escatimado esfuerzo alguno? es la reflexión que me dispone a meditar. 